\title{
PROFESSORES DE EDUCAÇÃO FÍSICA E SUAS PRÁTICAS PEDAGÓGICAS EM CLASSES QUE ALUNOS COM DEFICIÊNCIA ESTÃO INSERIDOS ${ }^{3}$
}

\author{
Anne Caroline Duarte \\ Universidade Estadual do Oeste do Paraná, Cascavel, Paraná, Brasil. \\ Douglas Roberto Borella \\ Universidade Estadual do Oeste do Paraná, Cascavel, Paraná, Brasil. \\ Gabriela Simone Harnisch \\ Universidade Estadual de Campinas, Campinas, São Paulo, Brasil. \\ Robson Frank \\ Universidade Estadual do Oeste do Paraná, Cascavel, Paraná, Brasil. \\ Angela Schone \\ Universidade Estadual do Oeste do Paraná, Cascavel, Paraná, Brasil.
}

\begin{abstract}
Resumo: O objetivo do presente estudo foi de verificar as Práticas Pedagógicas utilizadas pelos professores de Educação Física, atuantes em turmas do ensino fundamental - anos iniciais, onde estão inseridos alunos com deficiência. Para tanto, utilizou-se da pesquisa descritiva observacional, com análise mista. Foram observadas 25 aulas, de cinco (5) professores, utilizando-se de um roteiro de campo. Os resultados demonstraram que as Práticas Pedagógicas utilizadas pelos professores promoveram parcialmente a inclusão dos alunos com deficiência, de modo que os métodos de ensino mais eficientes para a promoção da inclusão foram os menos utilizados.
\end{abstract}

Palavras-chave: Crianças com deficiência; Pessoas com deficiência; Educação Física; Educação.

\section{Introdução}

As práticas pedagógicas envolvem um processo social que visam à ação educativa, sendo uma intermediação entre o aluno, o professor e o contexto escolar. Libâneo (1994, p. 70), ressalta que a prática pedagógica contempla três dimensões: "o saber, saber ser e o saber fazer", envolvendo assim, o aspecto pedagógico, o político e o técnico, os quais juntos visam a transformação social do ser humano e a construção de uma sociedade democrática. Portanto, a escola deve proporcionar subsídios para a formação de cidadão crítico, consciente dos seus direitos e deveres.

Diante do exposto, a busca pelo conhecimento deve contemplar as peculiaridades e potencialidades de todos os alunos e, neste ínterim, o professor desempenha a tarefa primordial de desenvolver ações e aplicar práticas educativas, adequando seus conceitos didático-metodológicos, sua postura pedagógica frente à necessidade do alunado, desenvol- 
vendo princípios fundamentais para formação uma sociedade, resultando suas ações em saber concreto.

Para fins deste estudo, o tema contemplado pelos pesquisadores pautou-se nos pressupostos de Libâneo (1994), o qual entende que a prática pedagógica deve estar presente no processo de ensino, de modo que o professor possa atuar como o mediador dos conhecimentos e que estes sejam assimilados pelos alunos.

Para Libâneo (1994, p. 50), os Métodos, Meios e Estratégias de Ensino objetivam uma prática pedagógica de qualidade no contexto escolar. Os Métodos de Ensino são determinados pela relação objetivo-conteúdo e referem-se aos meios para alcançar objetivos gerais e específicos do ensino, implicando numa sessão planejada e sistematizada de ações, tanto para professores quanto para os alunos. Ainda, Libâneo (1994) classifica os Métodos da seguinte forma: Método de exposição ${ }^{4}$; Método exposição verbal ${ }^{5}$; Método de ilustração ${ }^{6}$; Método demonstração ${ }^{7}$; Método de exemplificação ${ }^{8}$; Método de trabalho independente ${ }^{9}$, Método de elaboração conjunta ${ }^{10}$; Método de Trabalho em Grupo $^{11}$; e, Método de Trabalho Individual ${ }^{12}$.

Por outro lado, os Meios de Ensino são os recursos materiais utilizados pelo professor e pelos alunos no processo de ensino. Equipamentos podem estar relacionado com o ensino indiretamente, tais como: quadro, recursos de multimídia, giz, pincel atômico (LIBÂNEO, 1994).

Já, as Estratégias de Ensino constituem-se na maneira como o professor ensina (LIBÂNEO, 1994), sendo também entendida por Nérici (1983, p. 285) como o "recurso didático de que o professor lança mão do método de ensino, na direção da aprendizagem".

Diante deste contexto, precisamente quando nos reportamos as questões envolvendo as práticas pedagógicas utilizadas pelos professores em suas aulas, vemo-nos diante de alguns questionamentos frente a educação de alunos com deficiência: quais seriam as ações essenciais para a implementação de práticas pedagógicas condizentes com as necessidades dos alunos com deficiência onde os mesmos encontram-se inclusos no ensino regular? Com

4 O Método Exposição trata-se de quando os conhecimentos, habilidades e tarefas são apresentadas, explicadas ou demonstradas pelo professor; sendo que a atividade dos alunos é receptiva (LIBÂNEO, 1994).

O Método Exposição Verbal objetiva explicar de modo sistematizado quando o assunto é desconhecido ou quando as ideias que os alunos trazem são insuficientes ou imprecisas (LIBÂNEO, 1994).

6 O Método Ilustração é uma forma de apresentação gráfica de fatos e fenômenos da realidade, por meio de gráficos, mapas, esquemas, gravuras, etc., por meio dos quais o professor enriquece a explicação da matéria (LIBÂNEO, 1994).

7 O Método Demonstração envolve uma forma de representar fenômenos e processos que ocorrem na realidade, ele acontece em explicações do estudo do meio (LIBÂNEO, 1994).

$8 \quad$ O Método de Exemplificação é um importante meio auxiliar da exposição verbal principalmente nas séries iniciais do ensino de $1^{\circ}$ grau, o qual ocorre quando o professor escreve uma palavra e solicita que os alunos observem e depois repitam, quando o docente lê em voz alta (LIBÂNEO, 1994).

9 O Método de Trabalho Independente dos alunos consiste em tarefas, dirigidas e orientadas pelo professor, para que os alunos as resolvam de modo relativamente independente e criador (LIBÂNEO, 1994).

O Método de Elaboração Conjunta é uma forma de interação ativa entre o professor e os alunos visando à obtenção de novos conhecimentos, habilidades, convicções e atitudes (LIBÂNEO, 1994).

11 O Método de Trabalho em Grupo ocorre pro meio de atividades onde os alunos reúnem-se em grupo a fim da equipe alcançar o objetivo proposto pela atividade (LIBÂNEO, 1994).

12 O Método de Trabalho Individual é utilizado quando os alunos possuem dificuldade de relacionarem-se com os colegas e envolverem-se em grupo, dessa forma torna-se importante trabalhar atividades individualizadas (LIBÂNEO, 1994). 
relação às aulas de Educação Física, como tornar "efetiva" a participação destes alunos pensando em práticas pedagógicas adequadas onde respeita-se as diferenças?

Falar de educação inclusiva é falar de transformação, na busca de possibilidades alternativas e não meramente ingênuas. Na compreensão destas questões, reside-se as possibilidades de avaliar as práticas pedagógicas utilizadas por professores de Educação Física para efetivação de tal processo, de modo a viabilizar formas para sua concretização. Porém, para que este objetivo possa efetivar-se, torna-se conveniente a reestruturação/readequação de métodos, estratégias e meios que possibilitem a transformação das práticas escolares por parte dos professores.

Deste modo, entendemos que a Educação Física como componente curricular não deve ficar apática, indiferente ou neutra em relação ao movimento da educação inclusiva, e sim fazer parte do currículo oferecido pela escola. Esta disciplina pode constituir-se como um adjuvante ou um obstáculo adicional a que a escola seja (ou se torne) mais inclusiva (RODRIGUES, 2003).

De acordo com Cidade e Freitas (2002); Seabra (2008), alguns elementos devem nortear a Educação Física para ser inclusivo, onde devem ser consideradas as restrições funcionais e fisiológicas do aluno com deficiência, de modo a oferecer-lhe oportunidades de movimentos mais favoráveis, que promovam desafios a sua superação e desenvolvimento de suas potencialidades.

Sobretudo, as práticas pedagógicas constituem o fator primordial para alcançar as metas propostas, de modo a estimular maior autonomia de movimento e possibilidades motoras, mais propícias às soluções de problemas do seu cotidiano, seja no contexto escolar ou na vida diária.

Ainda, Cidade e Freitas (2002) comentam que os professores de Educação Física podem contribuir com o processo inclusivo, tornando-se necessário que eles reconheçam às particularidades de seus alunos atrelados a condição de deficiência, tais como: caracterização da deficiência; origem e etiologia; se adquirida, a idade de aquisição da deficiência e suas implicações no processo de desenvolvimento global da criança.

Neste mesmo pensar, Cidade e Freitas (2002) e Mauerberg-deCastro (2005), acrescentam que algumas adaptações ${ }^{13}$ podem ser realizadas pelos professores de Educação Física a fim de favorecer a inclusão de alunos com deficiência em suas aulas: a) adaptação de material e sua organização na aula (tempo, espaço, recursos e materiais disponíveis); b) adaptação no programa (planejamento, atividades e avaliação); c) aplicação de uma metodologia adequada à compreensão dos alunos, usando estratégias e recursos que despertem neles o interesse e a motivação, por meio de exemplos concretos, incentivando a expressão e a criatividade; d) adaptações de objetos e conteúdos, adequando-os, quando for necessário, em função das necessidades educativas especiais, dando prioridade a conteúdos e objetivos próprios, definindo os mínimos e introduzindo os novos quando for preciso.

Diante do exposto, surge a seguinte pergunta norteadora deste estudo: quais as práticas pedagógicas utilizadas pelos professores de Educação Física atuantes em turmas do ensino fundamental - anos iniciais, onde estão inseridos alunos com deficiência? Para responder a

13 Adequar a exigência da tarefa ao nível de desempenho do executante. Cada vez que se altera a exigência e as condições de desempenho de uma atividade de forma que um dado executante possa realizá-la ou envolver-se num processo de aprendizagem que está sendo adaptada. Tornar uma atividade mais exigente em termos perceptivos, tomada de decisão, desempenho motor ou elaboração cognitiva é também adaptar ( ROGRIGUES, 2006, p. 41). 
este questionamento pretendeu-se verificar quais práticas pedagógicas são utilizadas por professores de Educação Física em turmas do ensino fundamental - anos iniciais, onde estão inseridos alunos com deficiência.

\section{Métodos}

Caracterização da pesquisa

O estudo foi delineado pela pesquisa descritiva observacional, com análise mista qualitativa e quantitativa, seguindo os princípios de Thomas, Nelson e Silverman (2012).

Participantes da pesquisa

Participaram do estudo cinco (5) professores, os quais apresentavam em suas turmas alunos com deficiência. Destes, quatro (4) do gênero feminino e um (1) do gênero masculino, todos com formação plena em Educação Física, com faixa etária entre vinte e oito (28) à trinta e dois (32) anos.

O período que esses cinco (5) professores lecionam oscila sete (7) à dez (10) anos, tratando-se do tempo de experiência no trabalho com alunos com deficiência 4) professores relataram que trabalham à três (3) anos com esses alunos e apenas um professor estava no primeiro ano de serviço com o público citado. Cada professor recebeu a designação fictícia de P1, P1, P3, P4 e P5. O professor P1 lecionava em turma que estava inserido aluno com paralisia cerebral, enquanto o P2 ministrava aula em turma com aluno com deficiência auditiva. Já o professor P3, P4 lecionavam em turmas com alunos com deficiência visual (baixa visão), e o P5 em turma com aluno com deficiência intelectual. Desses estudantes citados quatro (4) são da rede privada e dois (2) da rede pública de ensino, pertencentes ao município de Marechal Cândido Rondon/PR.

Instrumentos para coleta dos dados

O instrumento para a coleta de dados foi composto por um roteiro de observação, elaborado por Mahl (2012). Contudo, o mesmo sofreu algumas alterações para atender os objetivos propostos nesta pesquisa. Dentre as alterações pode-se citar a inserção de anotações em relação a didática dos professores observando os aspectos: ao iniciar assunto ele realizou explanação/apresentação do mesmo, atividades desenvolvidas na aula seguiram a sequência no nível de complexidade (simples para o complexo), o professor realizou avaliação da aula para verificar o que os alunos aprenderam.

Também foram acrescentadas anotações dos meios (materiais) e métodos de ensino utilizadas pelos professores no desenvolvimento das aulas, ou seja, se a explicação do professor contemplou exemplos práticos, as atividades são desenvolvidas pelos alunos de forma independente.

Procedimentos para coleta de dados

Foram identificadas nas escolas da cidade de Marechal Cândido Rondon/PR professores de Educação Física que apresentavam em suas turmas alunos com deficiência, onde foram contatados pelos pesquisadores com o intuito de explanar o objetivo do estudo e verificar o interesse em participar da pesquisa. Mediante o parecer favorável dos mesmos, foi 
entregue o TCLE e colhido a assinatura dos mesmos. Após isto, foram realizadas as observações das aulas.

O processo de coleta de dados transcorreu com a observação de cinco (5) aulas por professor, perfazendo um total de 25 aulas observadas.

Análise dos dados

'Os dados foram analisados por meio do método misto, seguindo os pressupostos de Thomas, Nelson e Silverman (2012) e a análise qualitativa foi organizada por meio da narrativa analítica proposta por esses autores. Os dados quantitativos foram tabulados e categorizados conforme Libâneo (1994). Os resultados foram apresentados graficamente.

\section{Resultados}

As respostas relativas a prática pedagógica adotada pelos professores nas aulas de Educação Física serão apresentadas a seguir segundo a classificação de Libâneo (1994). Para apresentação dos resultados cada professor recebeu a designação fictícia de P1, P1, P3, P4 e P5.

Cabe destacar que algumas atividades desenvolvidas pelos professores participantes do estudo tiveram a possibilidade de ser classificadas em mais de um Método. Exemplificando: para realizar a explicação de alguma atividade os professores iniciavam utilizando do Método Exposição Verbal. Todavia, a mesma também pode ser classificada no Método de Trabalho Individual conforme a disposição da turma de alunos naquele momento.

A representatividade de utilização de cada Método de Ensino frente às atividades desenvolvidas pelos professores de Educação Física em suas aulas estão representadas na Figura 1:

Figura 1- Quantidade de atividades utilizadas em todos os Métodos.

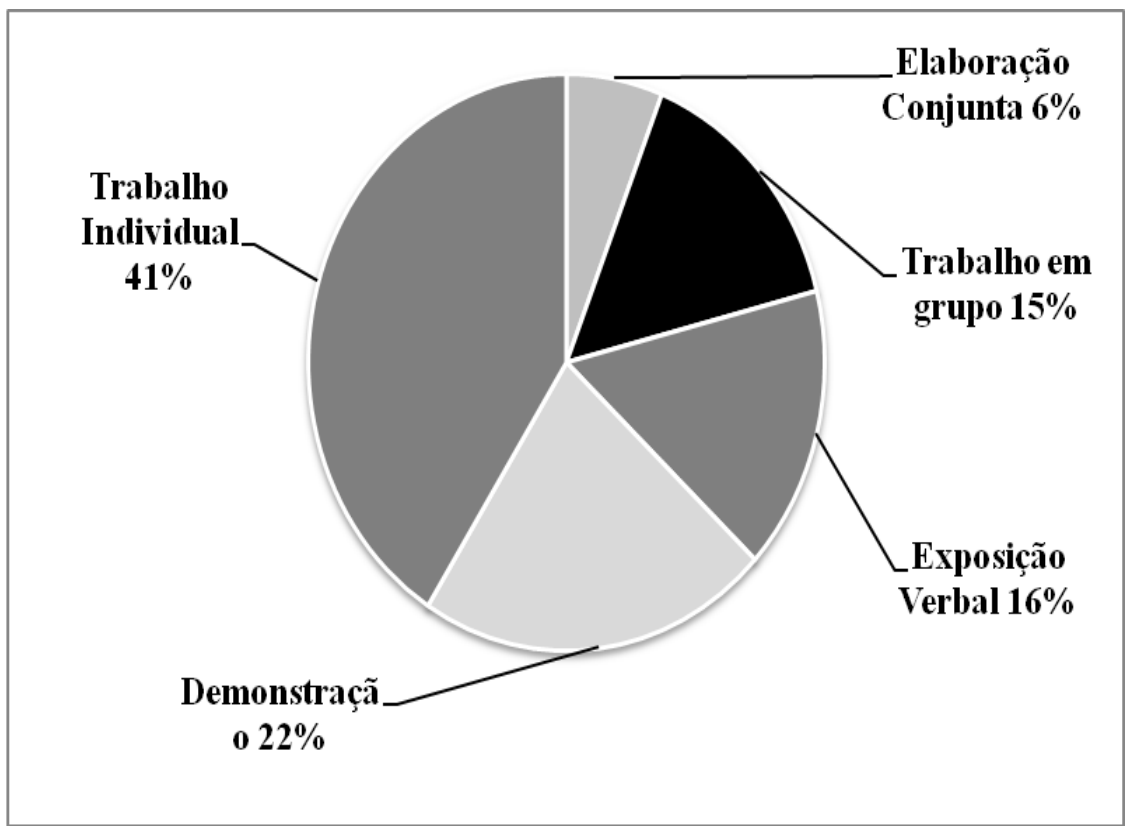


De acordo com as observações realizadas, constatou-se que o Método de Exposição Verbal foi o método mais utilizado pelo professor P5, cujo método foi empregado em 11 atividades, correspondendo a $25 \%$. Já os professores P1, P2 e P3 basearam-se neste método durante a aplicação de quatro (4) atividades, com percentual de $20 \%$. Por sua vez, a professora P4 utilizou-se deste método em três (3) atividades, representando $15 \%$.

Quanto ao Método Demonstrativo, os resultados revelaram que a professora P1 utilizou-se deste método em sete (7) atividades, compreendendo $26 \%$. A professora P2 empregou em seis (6) atividades, obtendo o percentual de $22 \%$, enquanto as professoras P3 e P4 o percentual foi de $18 \%$ e $19 \%$ respectivamente. Ambas utilizaram na explicação de cinco (5) atividades. Todavia, os Métodos Ilustração e Exemplificação não foram utilizados por nenhum professor. Compreende-se que houve assimilação dos alunos no modo a ser realizada as atividades sem a necessidade dos professores utilizarem dos mesmos.

Tratando-se do Método Elaboração Conjunta observou-se o emprego em três (3) das atividades pelas professoras $\mathrm{P} 1$ e $\mathrm{P} 4$, com os percentuais de $37 \%$ e $38 \%$ respectivamente, enquanto o professor P5 baseou-se na explicação de três (3) atividades obtendo $25 \%$. Já as professoras P2 e P3 não utilizaram-se.

Outro Método empregado pelos professores foi o Método de Trabalho em Grupo, sendo aplicado principalmente pela professora P1 em seis (6) atividades perfazendo $33 \%$. A professora P2 utilizou-se deste método em duas (2) atividades, somando 11\%. Já os professores P3 e P5 aplicaram em três (3) atividades, somando 17\%, enquanto a professora P4 empregou em quatro (4) atividades, correspondendo a $22 \%$.

Constatou-se que o Método de Trabalho Individual foi o mais utilizado por todos os professores, sendo empregado pelas professoras P1, P4 e P5 em 11 atividades, perfazendo $21 \%$ da prática pedagógica de cada professor, enquanto os professores P2 e P3 basearam-se em dez e oito (8) atividades respectivamente, obtendo-se os percentuais de $20 \%$ e $16 \%$.

Diante deste cenário acerca dos Métodos de Ensino utilizados pelos participantes do estudo, constatou-se que o Método Individual foi utilizado em $41 \%$ das atividades desenvolvidas pelos professores de Educação Física, o Método Demonstrativo foi aplicado em 22\% das atividades, o Método de Exposição verbal em 16\%, o Método de Trabalho em Grupo em $14 \%$ e o Método Elaboração Conjunta em 6\%. Os dados citados estão apresentados a seguir na Figura 2. 
Figura 2 - Percentual de todos os Métodos utilizados pelos professores

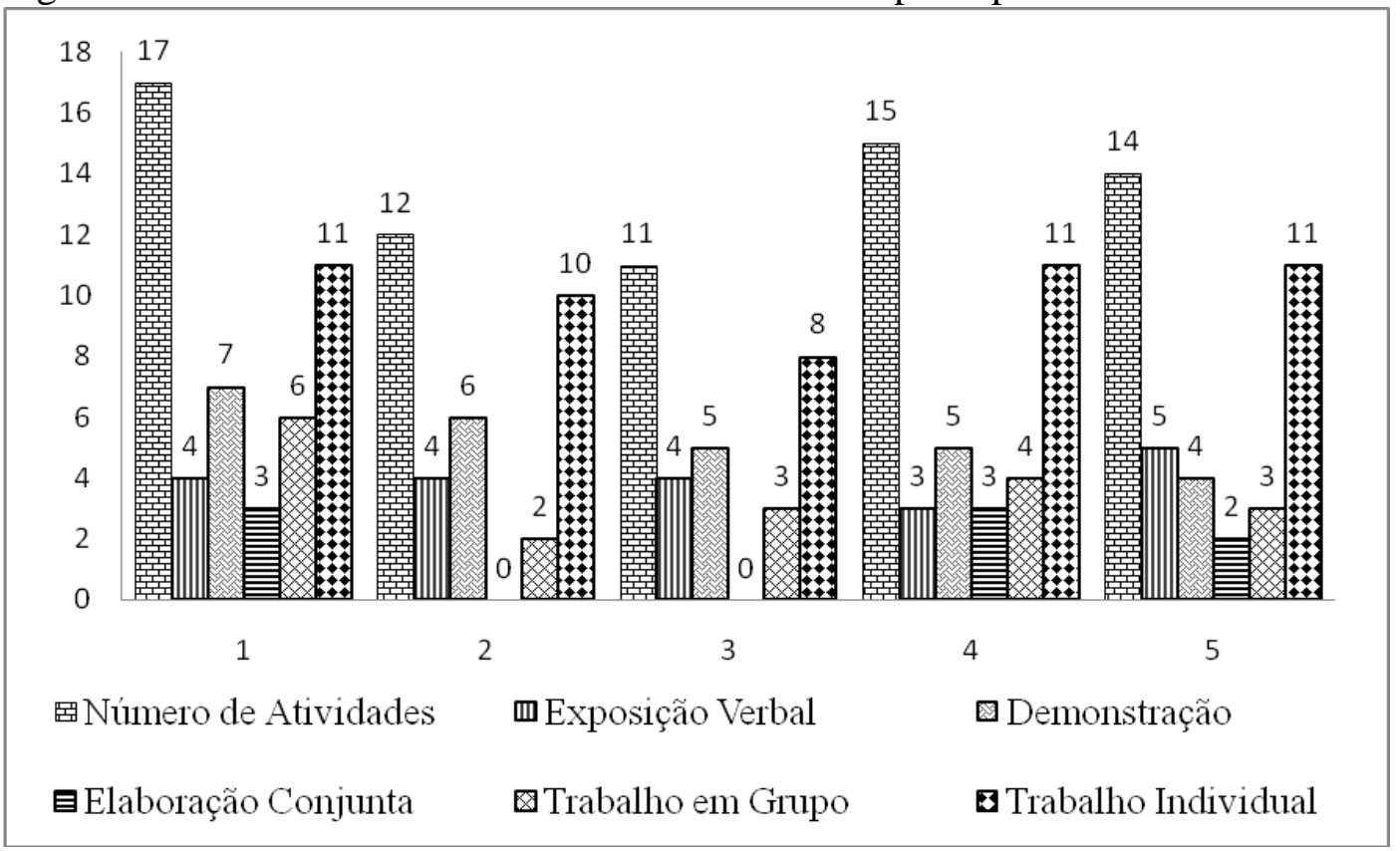

Por outra parte, verificou-se uma diversidade de Estratégias de ensino empregadas pelos professores. Em relação às Estratégias utilizadas pelo professor P1, observou-se que em momentos ele chamava a turma para aproximar-se dele e então explicava a atividade. Em alguns momentos da aula após ele perceber que os alunos não haviam compreendido a explicação ele utilizou-se de outro Método. Também solicitava que os demais alunos auxiliassem o aluno com paralisia cerebral visando promover socialização da turma com esse aluno e quando havia necessidade o professor explicava individualmente a esse aluno.

Em relação às Estratégias de ensino adotadas pelo professor P2, pode-se observar que para explicar as atividades primeiro ele chamava toda a turma próximo dele e solicitava que os alunos posicionassem sentado e daí sim explicava, facilitando a visualização do aluno com deficiência auditiva da boca e permitindo a leitura labial, também explicava pausadamente com a utilização de gestos. Também utilizou de demarcações na quadra esportiva para desenvolver a atividade de pegador linha, porque através dessa estratégia pedagógica a professora permitiu que os alunos conhecessem as linhas que delimitam o campo, preparando a turma para o conteúdo jogos pré-desportivos que conforme a Associação dos Professores do Município do Paraná (AMOP, 2007) prevê o trabalho deste conteúdo no $4^{\circ}$ e $5^{\circ}$ ano, além disso auxilia o aluno com deficiência auditiva a localizar o espaço que deve percorrer. $\mathrm{O}$ professor P2 também empregou a Estratégia de mudanças de regras. Normalmente esse procedimento ocorria durante o conteúdo jogos.

As Estratégias de ensino adotadas pelo professor P3 revelou que na maioria das vezes quando iria explicar as atividades solicitava que todos os alunos sentassem e fizessem silêncio. Desta forma, ele aproximava-se do aluno com deficiência visual (baixa visão) para que o mesmo pudesse localiza-lo pelo som da voz e no decorrer das atividades também empregava sons, como exemplo, na aula em que o professor desenvolveu estafeta o mesmo foi ao lado desse aluno batendo palmas.

Já o professoro P4 utilizou como Estratégia o posicionamento de cada aluno ao lado um do outro para realizar a explicação. Desta forma, facilitava a visualização do professor da 
turma e inclusive do aluno com deficiência auditiva e além dis so o som da voz era facilmente propagado. Também o professor, escolhia alunos diferentes para auxiliar o aluno com deficiência auditiva. E em conjunto com os alunos, produziram diferentes regras, principalmente no momento de atividades envolvendo pegadores, onde produziam diferentes formas de "salvar" os colegas pegos.

Por fim, as Estratégias adotadas pelo professor 5 pôde ser constatada em momentos que os alunos apresentavam mal comportamentos durante as aulas, tais como: brigas, conversas em demasia, entre outros. O professor solicitava que os mesmos não participassem das atividades e sim retornavam a aula após uma conversa com o professor.

Em momentos esse professor adotou explicações individualizadas quando percebia que os alunos encontravam dificuldade, inclusive com o aluno com deficiência intelectual e em alguns momentos possibilitava que alguns alunos ajudassem esse colega.

Em relação aos Meios e Conteúdos de Ensino, observou-se que quatro (4) professores trabalharam em todas as aulas o conteúdo Jogos e Brincadeiras, ao passo que um (1) professor desenvolveu o conteúdo Ginástica. Os meios utilizados durante as aulas foram: corda, arco, bola e cones.

\section{Discussão}

Para promover a discussão em relação às Práticas Pedagógicas desenvolvidas pelos cinco (5) professores participantes do estudo frente à inclusão de alunos com deficiência em suas turmas, os resultados serão discutidos em tópicos correspondentes aos elementos Método, Estratégia de Ensino e Meios de Ensino.

Quanto ao Método de Exposição Verbal, verificou-se que foi utilizado pelos professores em atividades conhecidas pelos alunos dentre essas o pegador pedra, ponte e árvore, alerta. Observou-se também o uso das instruções verbais durante a execução de alguma habilidade e/ou tarefa, onde os professores sabiam qual a função que o aluno deveria executar naquele momento da aula, sendo conceituado por Mahl (2012) de habilidade fechada.

Conforme Libâneo (1994), no Método Exposição Verbal os conhecimentos, habilidades e tarefas são apresentadas, explicadas ou demonstradas, entre as formas de exposição estão à exposição verbal, a demonstração, a ilustração e a exemplificação. $O$ principal objetivo é explicar o conteúdo de modo sistematizado.

Os dados averiguados no estudo são semelhantes à pesquisa desenvolvida por Mahl (2012), na medida em que constataram a utilização da informação verbal (Método de Exposição Verbal) foi maior em habilidades motoras fechadas, pode ser resultado dessas habilidades serem previsíveis, ou seja, o professor sabe qual a habilidade que o aluno executará, portanto, pode auxiliá-lo no fornecimento de informações para ele.

Por outro lado, o Método Demonstrativo foi empregado durante a realização de atividades complexas como exemplos pode-se citar as estafetas, atividades onde os alunos executavam mais de uma função (driblar a bola e correr). Em contrapartida, constatou-se que os Métodos Ilustração e Exemplificação não foram utilizados por nenhum dos professores avaliados. Acredita-se que tal fato seja decorrente da disciplina Educação Física ter maior enfoque na execução das práticas motoras, o que torna mais frequente a utilização de outros métodos, tais como o Método Demonstrativo.

Corroborando com a literatura, verificou-se a semelhança destes resultados com o estudo desenvolvido por Tonello e Pellegrini (1998), pois mostram que, para ensinar as 
habilidades motoras à fase da aula em que o modelo demonstrativo foi utilizado com maior frequência foi à principal.

Por sua vez, o Método Elaboração Conjunta foi empregado por três (3) professores no decorrer de seus diálogos com os alunos, a fim de estimular a criatividade e participação na construção das aulas, proporcionando-lhes maior autonomia no processo de ensino.

Segundo Seabra (2008), o Método Elaboração Conjunta é uma forma de interação ativa entre o professor e os alunos visando à obtenção de novos conhecimentos. A literatura também nos mostra semelhante pesquisa desenvolvida por Correia (1996), o qual enfatizou que o Método de Elaboração Conjunta foi eficaz para promover um planejamento participativo de todos os alunos investigados nas aulas de Educação Física.

No transcorrer das observações relativas ao presente estudo, averiguou-se que o Método de Trabalho em Grupo foi empregado por todos os professores, principalmente nas atividades pré-desportivas em que os alunos reuniram-se em grupo a fim da equipe alcançar o objetivo. Também foi um Método empregado em atividades de pega-pega, em que os pegadores davam as mãos para os alunos e deveriam pegar os demais. Tal alternativa proporcionou um feedback para orientação e mobilidade de alunos com deficiência durante as aulas de Educação Física.

Estes resultados também vão de encontro com o estudo desenvolvido por Costa e Nascimento (2006), onde os autores mencionaram como procedimentos metodológicos utilizados o trabalho em grupo, os questionamentos, os debates.

Contudo, o Método de Trabalho Individual foi o mais utilizado por todos os professores investigados, cuja preferência por atividades individuais pode ser atribuída à faixa etária dos alunos entre seis (6) a oito (8) anos. Ferreira (1994) relata que a característica dessa idade e a falta experiência no relacionamento com as demais pessoas ocasionam insegurança.

Considerando as Estratégias de Ensino utilizadas pelos professores, o professor P1 oportunizou o contato com o material a ser utilizado na aula antes de desenvolver as atividades. Outra estratégia diz respeito ao inicio de implementação das atividades em espaço reduzido (meia quadra) e no decorrer das atividades o espaço era ampliado. Desta forma, pode-se perceber a preocupação do professor para que os alunos realmente assimilassem o conhecimento, utilizando-se de outra estratégia visando auxiliar na aprendizagem.

Esta Estratégia também foi observada por Santos e Matos (2004), pois mencionam que um professor queria que as atividades fossem compreendidas e fixadas pelos alunos. Além disto, os estudos de Rodrigues e Darido (2008) revelam que os sujeitos observados em sua pesquisa iniciavam as aulas a partir de uma situação-problema para os alunos resolvessem com suas vivências.

Percebe-se que o professor esforçava-se no intuito de promover estímulo para a participação dos alunos. Desta forma, constata-se que o mesmo é comprometido com a prática docente. $\mathrm{O}$ resultado também foi encontrado em estudo realizado por Rodrigues e Darido (2008), onde expressam que o professor mostrava-se bastante interessado e preocupado com o trabalho docente e também com as necessidades de seus alunos.

A respeito das estratégias utilizadas pelos professores, destaca-se a utilizada por P2 e P3 durante a atividade denominada "alerta, stop" (atividade em que o aluno arremessa a bola e chama algum colega, quem foi chamado deve tentar pegar a bola e falar alerta ou stop todos alunos param no lugar quem estiver de posse da bola deve tentar arremessar em um colega). Os mesmos constataram que os meninos chamavam somente colegas do mesmo gênero e as meninas também mencionavam apenas as colegas. A partir disto, as professoras solicitaram que os alunos chamassem pelos colegas do gênero oposto. 
Acredita-se que a Estratégia supracitada é de extrema relevância, por que na idade entre seis (6) a dez (10) anos meninos e meninas encontram dificuldades de relacionarem-se por isso da importância do papel do professor para auxiliar a interação entre ambos. Bee (1986) contribui com os seus ensinamentos comentando que o relacionamento entre companheiros durante os anos escolares é interessante, pois os grupos que as crianças formam normalmente são do mesmo gênero.

Já o professor $\mathrm{P} 4$ utilizou como estratégia o posicionamento de cada aluno ao lado do outro para efetuar a explicação. O mesmo também adotou o Método Demonstrativo como alternativa para ser melhor compreendido durante suas explicações. O procedimento foi observado na aula em que trabalhou com arcos. Primeiro ele empregou o Método de Exposição verbal. Como alguns alunos não o compreenderam utilizou-se do Método Demonstrativo.

Esta estratégia também observou-se no estudo realizado por Rodrigues e Darido (2008), pois os mesmos afirmam que era comum o professor convidar os alunos a participarem ativamente das decisões durante as aulas.

O professor P5 adotou em suas aulas a Estratégia de abordar o tema Cultura Corporal e Corpo ${ }^{14}$ pertencente aos elementos articuladores dos conteúdos da Educação Básica que competem ao professor de Educação Física abordar esse conteúdo, conforme o Departamento da Educação básica do estado do Paraná (2008). Como exemplo, na aula em que após os alunos realizarem atividade estafeta onde haviam corrido o professor solicitou que as crianças posicionassem a mão no peito e sentissem os batimentos cardíacos e então questionou os alunos se o ritmo cardíaco estava acelerado e o motivo.

A estratégia supracitada também foi observada em estudo realizado por Seabra Júnior (2008); Rodrigues e Darido (2008), onde a interdisciplinaridade pode e deve ser utilizada no decorrer das aulas, porque através desse procedimento os conhecimentos são associados com os acontecimentos do cotidiano dos alunos estimulando-os.

Quanto aos conteúdos e meios de ensino utilizados pelos professores, constatou-se que quatro (4) professores (P1, P2, P3 e P5) trabalharam o conteúdo Jogos e Brincadeiras e um (1) desenvolveu o conteúdo Ginástica. Em relação os meios utilizados constatou-se que todos os professores utilizaram-se da bola, arco e corda. Observou-se que os materiais utilizados não limitaram o ensino, pois os professores utilizaram poucos meios, contudo com criatividade conseguiram desenvolver o conteúdo proposto.

É interessante ressaltar que os conteúdos desenvolvidos pelos professores diferem-se da maioria daqueles trabalhados durante as aulas de Educação Física, pois através de pesquisas em outros estudos constatou-se que ainda o esporte é um dos conteúdos mais trabalhados pelos professores.

Exemplificando tal momento, o estudo de Mahl (2012) demonstrou que o conteúdo esporte foi predominante em todos os dias das aulas práticas. Outro estudo realizado por Rodrigues e Darido (2008) os resultados obtidos foram similares, pois os alunos solicitavam à prática do futebol e eram atendidos.

De modo geral, observou-se baixas porcentagens obtidas pelos Métodos de Trabalho em Grupo e Método Elaboração Conjunta que poderiam vir a auxiliar no processo inclusivo,

14 Elemento articulador conforme Pistrak (2000) denomina por Sistema de Complexos temáticos, isto é, permite ampliar o conhecimento da realidade estabelecendo relações e nexos entre os fenômenos sociais e culturais. 
pois, através do trabalho desenvolvido em equipe ocorre a interação e consequentemente a troca de conhecimentos e todos contribuem da sua forma no decorrer do processo educativo, desta forma, as diferenças físicas, sociais e cognitivas entre os alunos são minimizadas e "vistas" de forma contributiva e não menosprezadas.

Todavia, deve-se destacar que os alunos com deficiência realizaram as atividades de forma autônoma, promovendo a inclusão, na medida em que esses participaram da mesma forma que os demais alunos nas atividades desenvolvidas. Este aspecto é de relevância, pois essas pessoas devem ser vistas de forma igualitária merecendo respeito e dignidade, porque com os respectivos comportamentos estar-se-á auxiliando no processo inclusivo dessas pessoas.

Tratando-se das Estratégias de Ensino observou-se que três (3) dos professores utilizaram-se de desafios visando estimular os alunos ao desenvolvimento das atividades propostas.

Deste modo, acredita-se que as Práticas Pedagógicas reveladas no cotidiano dos professores observados corresponderam em grande parte as necessidades individuais dos alunos, principalmente dos alunos com deficiência, justificando-se que nem sempre os métodos, meios e estratégias de ensino desenvolvidos nas aulas de Educação Física corresponderam às capacidades motoras dos grupos e de cada aluno de modo particular.

\title{
TEACHER OF PHYSICAL EDUCATION AND EDUCATIONAL PRACTICES IN THAT CLASS STUDENTS WITH DISABILITIES ARE INSERTED
}

\begin{abstract}
The objective of the present study was to check the teaching practices used by teachers of physical education, active in elementary school classes-early years, where are students with disabilities. To this end, we used descriptive observational research, with joint analysis. 25 lessons were observed, five (5) teachers, using a script. The results showed that Pedagogical practices used by teachers partly promoted the inclusion of students with disabilities, so that the most efficient teaching methods for the promotion of inclusion were the least used.

Keywords: Children with disabilities; People with disabilities; Physical Education; Education.

\section{PROFESORES DE EDUCACIÓN FÍSICA Y PRÁCTICAS EDUCATIVAS EN LAS CLASES QUE SE INSERTAN LOS ESTUDIANTES CON DISCAPACIDADES}

Resumen: El objetivo de este estudio fue el de revisar las prácticas de enseñanza utilizados por los profesores de educación física, activa en clases-primeros años de escuela primaria, donde se incluyen los alumnos con discapacidades. Por lo tanto, se utilizó el análisis observacional descriptivo mixto. Se observaron 25 clases, cinco (5) profesores, utilizando un script. Los resultados mostraron que las prácticas pedagógicas utilizados por los docentes promueven parcialmente la inclusión de los estudiantes con discapacidad, por lo que los métodos de enseñanza más eficaces para la promoción de la inclusión fueron los menos utilizados.

Palabras-clave: los niños con discapacidades; Personas con discapacidad; Educación física; Educación. 


\section{Referências}

Associação dos municípios do Oeste do Paraná-AMOP (2007). Departamento de Educação. Currículo básico para a escola pública municipal: Educação Infantil e ensino Fundamental- anos iniciais - Cascavel: ASSOESTE.

CIDADE, R. E. A., FREITAS, P. S. Noções sobre Educação Física e desportos para portadores de deficiências: uma abordagem para professores de $1^{\circ}$ e $2^{\circ}$ grau. Uberlândia: INDESP, 2002.

CORREIA, W. R. Planejamento participativo e o ensino de educação física no $2^{\circ}$ grau. Revista Paulista de Educação Física. 43-48, 1996.

COSTA, L. C. A., NASCIMENTO, J. V. Prática pedagógica de professores de educação física: conteúdos e abordagens pedagógicas. Revista da Educação Física/UEM. 17 (2), 161 $167,2006$.

DARIDO, S. C. Educação física na escola: questões e reflexões. Rio de Janeiro: Guanabara Koogan, 2003.

FERREIRA, M.C.C. Construindo um projeto político-pedagógico para a formação de educadores no contexto da educação especial. Em: bicudo, M.A.V., Silva Jr., C.A. (eds.) Formação do educador e avaliação educacional: formação inicial e continuada. São Paulo, São Paulo: UNESP, 1999.

LEWGOY, A. M. B., ARRUDA, M. P. Novas tecnologias na prática profissional do professor universitário: a experiência do diário digital. Revista Textos e Contextos: coletâneas em Serviço Social, (2), 115-130, 2004.

LIBÂNEO, J. C. Democratização da Escola Pública: Pedagogia crítico-social dos conteúdos. São Paulo: Loyola, 1994.

MAHL, E. Práticas pedagógicas dos professores de Educação Física frente a inclusão de alunos com deficiência, (Dissertação de Mestrado). Universidade Federal de São Carlos, São Carlos, São Paulo, 2012.

MAUERBERG-deCASTRO, E. Atividade Física Adaptada. Ribeirão Preto/SP: Tecmed, 2005 .

MIOTO, R. C. T. A perícia social: proposta de um percurso operativo. Serviço Social e Sociedade, 67(1), 145-158, 2001.

NERECI, I, G. Didática: uma introdução. São Paulo: Atlas, 1983.

RODRIGUES, D. A. (2003). Educação Física perante a educação inclusiva: reflexões conceptuais e metodológicas. Revista da Educação Física/UEM. 14 (1), 67-74, 2003. 
RODRIGUES, A. E., DARIDO, C, S. As três dimensões dos conteúdos na prática pedagógica de uma professora de Educação Física com mestrado: um estudo de caso. Revista de Educação Física/UEM, 19 (1), 51-69, 2008.

SANTOS, C. R., MATTOS, S, C, T. A relação entre tendência e prática pedagógica dos professores de Educação Física de $3^{\circ}$ e $4^{\circ}$ ciclos do ensino fundamental. Revista Mackenzie de Educação Física e Esporte, 3 (3), 45-53, 2004.

SEABRA JÚNIOR, M. O. Estratégias de Ensino e Recursos Pedagógicos para o Ensino do Aluno com Deficiência Visual na Atividade Física Adaptada. (Tese de Doutorado) Faculdade de Filosofia e Ciências da Universidade Estadual Paulista, Marília, São Paulo, 2008.

SCHNEIDER, M. B. D. Subsídios para a formação pedagógica no cotidiano escolar inclusivo. Revista Educação Online, 2003.

SILVA, P. A., MACEDO, N, N., LIMA, C. V. Formação docente e práticas pedagógicas: Reflexões para o trabalho na perspectiva de uma educação inclusiva. Em: denari, E, F (ed.). Educação e Educação Especia - textos e (con)textos. São Paulo, São Paulo: Pedro e João editores, 2011.

SOUZA, A. M. Prática pedagógica: conceito, características e inquietações. In: IV Encontro ibero-americano de coletivos escolares e redes de professores que fazem investigação na sua escola, Lajeado, Rio Grande do Sul, Brasil, Julho, 2004.

THOMAS, J. R., NELSON, J. K., SILVERMAN, S. J. Métodos de pesquisa em atividade física. Porto Alegre: Artmed, 2012.

TONELLO, M. G. M., PELLEGRINI, M, A. A utilização da demonstração para aprendizagem de habilidades motoras em aulas de Educação Física. Em: Revista Paulista de Educação Física, 12 (2), 107-114, 1998.

Recebido em: 27/01/2014

Revisado em: 07/02/2015

Aprovado em: 25/02/2015

Endereço para correspondência:

robson_frank_91@ @otmail.com

Robson Frank

Universidade Estadual do Oeste do Paraná

Rua Universitária 1619

85819-110 Cascavel, Parana, Brazil 